\title{
PARA ONDE CAMINHA \\ O ENSINO DE PORTUGUÊS?
}

Maria José G. D. Foltran ${ }^{*}$

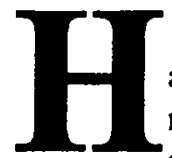

á pelo menos duas décadas, o ensino de lingua materna sofreu uma revisão exaustiva. Através de análises e reflexões, a prática tradicional foi repensada e uma série de propostas alternativas começaram a aparecer, delineando um caminho que teria como preocupação central o dominio da língua nas suas modalidades oral e escrita.

Assim, o ensino tradicional começou a ser questionado a partir de seus resultados. A extrema dificuldade de alunos, de modo geral, articularem um texto escrito após uma permanência de onze anos, pelo menos, na escola, levou os especialistas a pesquisas e discussões com o objetivo de encontrar as causas e buscar soluções. Essa reflexão, normalmente monopolizada por especialistas da área da educação, começou a ser enriquecida por contribuições decisivas da lingüistica, já que o que se discutia era o ensino de língua. A revisão das práticas tradicionais apontava a necessidade de mudanças não só metodológicas como também conceptuais. As pesquisas na área de aquisição da linguagem e na área de variação lingüística começaram a ser assimiladas pelo contexto educacional. Defendeu-se, a partir daí, a necessidade de partilhar esses conhecimentos com os professores, em especial com os alfabetizadores. A esse quadro podemos acrescentar, ainda, as contribuições da lingüistica textual, decisivas na área de compreensão e produção de textos. Diante das novas conquistas, constatou-se

* Universidade Federal do Paraná. 
que estávamos diante de uma concep̧̧̃o de linguagem diferente da que existia no ensino tradicional, e passou-se, portanto, a explicitar essa nova concepção e dela tirar novas posturas.

Com certeza, esse momento de revisão e reflexão constituiu um grande avanço teórico. Nunca o ensino de língua foi pensado de forma tão profunda $e$ séria como nessas últimas décadas. As contribuições que surgiram são inestimáveis. $\mathrm{O}$ que gostariamos de refletir neste momento é até que ponto esse avanço teórico resultou num avanço da prática em sala de aula? Acompanhando esse processo através de discussões acadêmicas e através de diversos cursos de capacitação para professores, pudemos perceber que essa nova postura foi de alguma maneira assimilada e que muitas mudanças foram efetivadas a partir daí. O que questionamos, no entanto, é a representatividade dessas mudanças considerando o sistema de ensino como um todo. Deixando de lado os exemplos pontuais de mudança, essa ou aquela escola, esse ou aquele professor que interagiu com a nova proposta e chegou a resultados extremamente positivos, não é difícil de perceber que o ensino de língua continua com as mesmas deficiências detectadas há alguns anos. Essa constatação exige uma nova revisão. Onde estaria situado o problema? Será que a nova proposta de ensino é inviável? Será que o sistema, da maneira como está estruturado, impede essa nova prática? Até que ponto as questões sociais barram a mudança? Seria ingenuidade nossa pensarmos que a resposta é uma só. Por outro lado, não seria nada produtivo dizermos que as dificuldades decorrem de uma série de fatores que, por agirem em conjunto, inviabilizam qualquer ação que queira reverter os resultados. Com certeza, seria muito difícil atacarmos todos os pontos ao mesmo tempo. Mas isso, ao invés de provocar uma acomodação, deve provocar a inquietação, a busca.

Revendo alguns textos' situados no momento histórico dessa discussão, pudemos refazer esse caminho, tentando observar os pontos chaves por eles abordados e analisar o seu encaminhamento dentro desse processo. Identificamos, de início, a abordagem da questão social que engloba o ensino, de modo geral, o professor e o aluno, de modo específico. A diminuição das verbas destinadas à educação nos últimos anos teve influências desastrosas no sistema, provocando o sucateamento não só das instalações como também do profíssionalismo docente. A partir dai, o professor começou a exercer atividades paralelas

1 Para essa revisão, tomamos por base os textos do SEMINÁRIO MULTIDISCIPLINAR DE ALFABETZAÇÃO (1983) e dos Anais do SEMINÁRIODE APRENDIZAGEM DE LINGUA MATERNA: uma abordagem interdisciplinar (1982), por abstrairem todas as críticas e preocupações, da época, relacionadas ao ensino de língua materna e por apresentarem alguns encaminhamentos que, a partir dai, começam a tomar vulto. 
para poder sustentar-se ou então abandonou a profissão diante de possibilidades mais rendosas. Para exemplificarmos melhor essa situação, basta olharmos, na época dos vestibulares, a procura que têm os cursos que habilitam ao magistério. Buscando cursos de maior prestigio social, os alunos que pretendem uma vaga nas universidades afastam a possibilidade de seguir a carreira do magistério. Isso leva a, pelo menos, dois caminhos igualmente danosos para a educação: de um lado, os cursos de licenciatura ficam sem possibilidade de fazer uma seleção mais apurada, permitindo a entrada de pessoas com um rendimento escolar bastante deficitário, o que vai redundar, quase sempre, num profissional com graves limitaçöes; de outro lado, cursos que atraem os alunos pelo seu prestígio social não oferecem grandes oportunidades de colocação no mercado, levando esses profissionais, muitas vezes, a enveredar para outras profissöes como o magistério. Nesses casos, apesar de, muitas vezes, termos pessoas de bom nível cultural, temos un profissional sem habilitação especifica, sem preparo para as questöes particulares do ensino.

Não é nossa intenção nos determos na análise dos problemas sócio-econômicos, até porque essa é a área que está mais longe de nosso alcance para que possamos interferir. É claro que, como cidadãos, devemos nos sentir na obrigação de provocar tais mudanças, mas temos consciência de que elas não seriam imediatas. Sabemos que essa situação, para ser alterada, depende de uma vontade politica ampla para mudar a cara desse pais através de uma divisão mais equacionada dos bens econômicos e culturais entre as classes sociais.

Outro ponto extensamente abordado nessa discussão foi a formação do professor. Procurou-se analisar as lacunas e fallhas por parte das teorias da educação e a preparação inadequada feita pelos cursos de formação de professores. Os estudos apontavam para a teoria lingüistica contemporânea que deveria constituir o principal fundamento de uma metodologia eficaz. Viu-se a necessidade de se desenvolver nos professores uma competência técnica especifica para utilizar as contribuiçōes da lingüistica que se traduziria, por exemplo, na capacidade de identificar em que pontos os métodos e manuais didáticos contradiziam os pressupostos e fundamentos dessa ciència.

A necessidade de capacitar o professor com um instrumental teórico era e continua sendo uma preocupação legítima. Sem dúvida nenhuma, o professor precisa ter fundamentos para encaminhar sua prática e são inegáveis as contribuições que esse conhecimento, quando devidamente utilizado, tem trazido para as salas de aula. No entanto, acima de tudo, o professor precisa conhecer e dominar o seu objeto de trabalho: a lingua, neste caso.

Ao participarmos de cursos de capacitação para professores, podiamos constatar que o devido domínio do instrumental teórico era apenas uma questão de tempo, de dedicação, de leitura. O que nos afligia, no entanto, era a consta- 
tação das dificuldades que esses professores tinham de expressar-se por escrito. Essa informação, muitas vezes, chegava até nós através das avaliações redigidas no final dos cursos. Diante desse fato, surgia a dúvida: será que começamos pelo ponto certo?

Esse é um problema que urge ser enfrentado, pois, no ensino, não há Pedagogia, Psicologia, Metodologia que substitua o conhecimento. No caso da língua, essa condição está, provavelmente, num nivel de exigência maior que das outras áreas de estudo. Por exemplo, é possivel pensarmos que um professor de Matemática possa ensinar, com eficiência, as operaçōes fundamentais, equações do primeiro e segundo graus mesmo sem saber trigonometria ou cálculo diferencial. Sabemos que isso não é o desejável nem o ideal, mas é possível. A lingua, no entanto, é um todo indivisivel e, portanto, não é possível facetarmos o seu conhecimento. $O$ professor, por exemplo, que trabalha com as séries iniciais precisa ter o mesmo dominio de lingua que o professor que trabalha com as últimas séries do segundo grau e, até mesmo, que um professor de terceiro grau. É absurdo pensarmos que é possível ter um domínio parcelado desse conhecimento, mesmo admitindo que essa aprendizagem nunca se encerra.

Nesse sentido, é importante que o professor, não só como transmissor desse conhecimento mas também como usuário da língua, tenha idéia clara de qual é a relação entre fala e escrita. A lingua escrita é uma entidade autônoma, diferente da língua falada e a relação entre elas não é direta. Portanto, o domínio de uma não implica o domínio da outra. Cada uma tem suas especificidades que exigem tratamento e trabalho apropriados e a apreensão desse conhecimento só se dá através de uma prática efetiva e de sucessivas interferências e observaçōes feitas por alguém que seja proficiente. É importante, no entanto, fazer uma ressalva. Conhecer e dominar os difcrentes processos semânticos, sintáticos $\mathrm{e}$ fonológicos da língua nos diferentes registros e modalidades é diferente de conhecer as teorias que descrevem esses processos. Esse conhecimento, sim, pode ser parcelado. As teorias que um professor alfabetizador precisa saber são diferentes das teorias que um professor universitário precisa para as suas atividades de ensino e pesquisa. É fundamental não confundirmos esses dois niveis. Esses profissionais precisam dominar o uso que podem fazer da lingua e conhecer as teorias que são imprescindiveis para a sua prática.

Sabemos de todos os esforços envidados para suprir as deficiências decorrentes da formação do professor através de cursos de capacitação, palestras e encontros. Com certeza, essas providências não foram em vão. Precisamos, no entanto, pensar em programas mais duradouros, que tenham em vista um continuum tanto no que diz respeito ao conteúdo como no que diz respeito às concepções que podem diferir de docente para docente. Cursos com duração mais longa permitiriam uma reflexão mais profunda e uma apreensão de 
conteúdos mais sólida. Esse seria um desafio a ser enfrentado pelos Núcleos de Ensino, pelas Secretarias de Educação e pelas Universidades. Mesmo que de imediato atingíssimos um número pequeno de professores, a qualificação alcançada permitiria que esse grupo funcionasse como multiplicador e assim iriamos sucessivamente atingindo grupos maiores.

Os manuais didáticos foram, também, alvo de diversas críticas e análises nos primeiros momentos dessa reflexão. ${ }^{2}$ Apoiados primeiramente na questão da ideologia, especialistas de difcrentes áreas chamaram a atenção para a grande carga de preconceito veiculada pelos materiais utilizados em sala de aula. Ancorados na visão de mundo da classe dominante, esses manuais fortaleciam as diferenças sociais e uma visão estereotipada da realidade. Enfatizava-se que a escolha do manual não poderia ser uma opção inocente, já que revelava-se ai uma postura política diante da educação. A par da análise ideológica, vinha uma apurada abordagem dos conteúdos: o que era trabalhado e como era trabalhado. Essas análises faziam consideraçōes à concepção de linguagem, concepção de aluno e concepção de educação que estavam subjacentes à seleção dos conteúdos, à seqüência adotada e ao tipo de atividades que eram propostas. A linguagem, trabalhada dentro de uma visão comportamentalista, era vista e repassada como um código isolado e independente do contexto social, o que justificava o encaminhamento metodológico que se restringia a exercícios de cópia, repetição c siga o modelo.

Apesar de todas essas criticas nāo terem sido condescendentes com os livros didáticos, não precisamos ir muito longe para perceber que essa luta foi de certa forma inócua, já que os mesmos livros, tāo criticados, estão, ainda, circulando nas escolas. A força do mercado editorial, principalmente na área de livros didáticos e paradidáticos, no Brasil, transcende qualquer parecer acadêmico. Por outro lado, não podemos dizer que a critica foi de todo em vão. Ao admitir-se que esse material era essencial para o trabalho do professor $\mathrm{e}$, muitas vezes, o único material impresso a que o aluno tinha acesso, houve um incentivo para uma nova produção, contcmplando a visão de linguagem explicitada pelos novos curriculos. Pcrcebemos, no entanto, que as criticas anteriores intimidaram os que tinham interesse em avançar nessa área. Mesmo assim, esse desafio foi enfrentado por algumas instituições, geralmente Secretarias de Educação, e por alguns grupos autônomos. De modo geral, são publicaçōes com uma tiragem bastante reduzida, o que torna dificil a sua divulgação e a competição com o material oferecido pelas grandes editoras. Podemos perceber, nos novos

2 Em relação aos livros didáticos, tomamos por base as criticas apresentadas no Cadernos do Eısino Fundamental, 1, da Secretaria de Estado da Educação do Paraná, de cuja elaboração fizemos parte. 
manuais, uma postura que tem como preocupação o ensino da língua no lugar do caráter normativo imposto pelo ensino de gramática.

Essas constatações nos levam a instaurar novas preocupaçōes. Em primeiro lugar, precisamos enfatizar a necessidade da continuidade de uma crítica em relação a esse material alternativo que está surgindo. Não a crítica intimidatória que acaba com as iniciativas, mas a discussão dos procedimentos adotados e a sua eficácia em sala de aula. Precisamos, portanto, fortalecer as iniciativas de explicitar o trabalho com a língua da maneira que é concebido nos novos currículos. E para não perder essa meta de vista, precisamos analisar os novos materiais propostos, o que, com certeza, trará contribuições para o seu aprimoramento. É importante lembrar que nenhum material didático faz por si só o trabalho que deve ser feito pelo professor. Esse recurso deve ser sempre visto como um meio e não como um fím em si mesmo. Em segundo lugar, precisamos nos lembrar que o combate ao ensino da gramática, da maneira como vem sendo feito, exige um trabalho que não pode ser de modo algum tímido, já que a disciplina gramatical, como afirma Batista (1991, p. 36), está há séculos associada ao uso escolar e é, por excelência, um objeto didatizado. Qualquer esforço nesse sentido é importante para aproximar a escola do caminho que desejamos, encontrando formas de exercícios adequadas às condições de possibilidades do ensino, possibilitando, assim, o rompimento com a tradição.

Por último, resta-nos lembrar que toda a discussão sobre o ensino de língua teve como eixo central uma nova concep̧̧ão de linguagem que pressupõe a compreensão do caráter indeterminado dos sistemas lingüísticos, dependentes das situações de enunciação, o que defíne ou não sua adequação. Essa proposta tem por base, por um lado, um comprometimento com a luta das camadas populares contra as discriminações que sofrem. Para tanto, deve-se encaminhar o ensino do Português como uma prática que visa à transmissão da variedade de prestígio não como aquela que deve se sobrepor à já dominada pelo aluno, mas como aquela variedade que a esta deve se acrescentar, já que é através dela que se transmitem os conhecimentos acumulados. Por outro lado, concebendose a língua como uma prática social e sua aprendizagem como construção ativa do sujeito, espera-se que o ensino de língua se centralize nas práticas de leitura e produção de texto em situaçōes o mais possivelmente reais e concretas de interlocução. Não há dúvida, entretanto, que as condições ligadas ao cotidiano escolar constituem poderosos inibidores de qualquer mudança.

Para exemplificar como certos procedimentos estão arraigados, gostariamos de comentar, aqui, um fato que nos foi narrado, ocorrido há pouco tempo. A professora de 2a. séric pediu aos alunos que formassem uma frase com as palavras comprar - sonho - supermercado. Não vamos nos preocupar aqui em questionar a validade e a eficácia desse tipo de exercício. Queremos apenas 
chamar a atenção para a visão instrumentalista que orienta o ensino. Ora, quem propõe um exercício desse tipo, pensa a língua como um sistema fechado e rígido e, portanto, estaria esperando respostas que teriam pequenos índices de variação, como: Comprei um sonho no supermercado, ou Compro sonhos no supermercado, $\mathrm{e}$ assim por diante. Mas a lingua não funciona dessa maneira e o aluno, como usuário dessa língua, sabe de suas possibilidades, conhece muito bem sua flexibilidade e, ai, temos um confronto entre a visão do professor c o saber do aluno. Tanto que essa professora, ao receber como resposta de un dos alunos a frase No sonho, comprei um supermercado, considerou-a errada.

Com certeza, todo o repensar do ensino de língua provocou uma instabilidade no processo. Precisamos cuidar, no entanto, para que isso não provoque um esvaziamento. Apesar das certezas que temos da necessidade de rever a prática tradicional, apesar do reconhecimento da proposta que emergiu a partir das contribuições da lingüística, a prática cotidiana do ensino de Português tem se mostrado impermeável às criticas e orientaçōes. Com certeza, essa resistencia se deve, em grande parte, às relaçōes económicas e sociais que continuam a reproduzir o modelo tradicional, até como una forna de garantir a hegemonia de certos valores. Outro fator que, possivelmente, oferece resistencia à mudança é a conecpção dominante relacionada à construção do saber com a qual a escola sempre trabalhou. Essa concepçāo supōe que o conteúdo ensinado seja passivel de ser recortado e distribuido através de grades que o dividem ao longo dos períodos escolares e, também, que seja passivel de ser traduzido objetivamente em exercicios para avaliações c exames que revelem as relaçōes dos alunos com o conhecimento. Como a proposta atual se pauta num conhecimento processual e assistemático, torna-se dificil adaptá-la aos moldes que a escola cultiva.

Dentro desse quadro, é imprescindivel que o diálogo entre a teoria $\mathrm{e}$ a prítica seja fortalccido. Por um lado, precisamos aproximar a escola que aí está do conlecimento e informaçōes imprescindiveis para o traballıo que almejamos. Por outro lado, precisamos didatizar essa prática que defendemos, de modo que a escola possa incorporá-la e, dessa forma, romper com a tradiçāo.

\section{RESUMO}

O fato de alunos, após onze anos de escolaridade, não apresentarem habilidades minimas relacionadas ao domínio de leitura e escrita, fez com que a metodologia de ensino de lingua materna fosse seriamente questionada. A partir dai, surgem novas propostas baseadas numa nova concepção de linguagem. No entanto, constata-se que a 
prática de sala de aula sofreu poucas alterações, apesar de terem sido registrados avanços teóricos efetivos nas últimas décadas. Esse artigo procura fazer uma revisão dos principais questionamentos feitos ao ensino tradicional e verificar o motivo do divórcio observado entre teoria e prática.

Palavras-chave: Lingua Portuguesa, Ensino de Lingua Materna, Educação.

\section{ABSTRACT}

The fact that students - after completing eleven years of schooling - still lacked basic abilities related to writing and reading, led to serious questionings about traditional methodology for teaching standard language. From that discussion, new proposals arose, based upon new concepts about language. However, it is now patent that, in spite of theoretical progress attested, classroom practice has changed little. This article reviews the arguments against traditional teaching methods, and searches the reasons why thory and practice have divorced.

\section{REFERÊNCIAS BIBLIOGRÁFICAS}

BATISTA, Antonio Augusto G. A gramática e o ensino de Português. Leitura: Teoria \& Prática, Revista Semestral da Associação de Leitura do Brasil, Campinas, v. 10, p. 29-38, jun. 1991.

PARANÁ, Secretaria de Estado da Educação. Cadernos do Ensino Fundamental, 1, Curitiba, 1991.

SEMINÁRIO APRENDIZAGEM DA LINGUA MATERNA: UMA ABORDAGEM INTERDISCIPLINAR. (1.: 1983: Brasília). Anais... Brasilia : Instituto Nacional de Estudos e Pesquisas Educacionais, 1983.

SEMINÁRIO MULTIDISCIPLINAR DE ALFABETIZAÇÃO. (1.: 1984:Brasília). Anais... Brasilia : INEP, 1984. 